\title{
MANEJO AGROECOLÓGICO EM AGROECOSSISTEMAS DIVERSIFICADOS NO BREJO E CARIRI DA PARAÍBA
}

\author{
AGROECOLOGICAL MANAGEMENT IN DIVERSIFIED AGROECOSYSTEMS IN \\ BREJO AND CARIRI OF THE PARAÍBA
}

\author{
Magna Maria Macedo Ferreira ${ }^{1}$ \\ Fabio Aquino de Albuquerque ${ }^{2}$
}

\begin{abstract}
RESUMO: Agroecossistemas são sistemas que tentam imitar os ecossistemas naturais; e manejo agroecológico consiste em um conjunto de práticas para esse fim. O objetivo desta pesquisa foi estudar a fertilidade do solo e a nutrição mineral das plantas de pequenas propriedades rurais submetidas ao manejo agroecológico em quatro municípios do semiárido brasileiro, dois no Brejo (Arara e Remígio) e dois no Cariri (Sumé e Prata) Paraibanos. Em cada um desses municípios foram estudadas duas propriedades que tinham em comum o fato de serem pequenas, utilizarem mão-de-obra familiar e práticas da agricultura orgânica, uma agricultura do tipo agroecológica. As culturas estudadas foram milho, feijão, algodão, fava, mandioca e jerimum. Os principais resultados obtidos foram: o $\mathrm{pH}$ do solo está um pouco abaixo da faixa considerada adequada para a maioria das culturas; a $\mathrm{MO}$ ainda está um pouco baixa, devendo as práticas sustentáveis continuarem sendo empregadas para o seu aumento; o teor foliar de $\mathrm{N}$ foi considerado adequado para algodão, jerimum, fava e mandioca, e baixo para milho e feijão; os teores de $\mathrm{P}$ nas folhas foram considerados baixos, apesar do seu teor no solo estar bom; os de $\mathrm{K}$ foram considerados bons apenas para o jerimum e a mandioca, destarte seu teor no solo estar bom; os teores de Ca foram bastante variáveis: baixo para feijão, fava e mandioca; adequado no jerimum; e alto para algodão e milho; os teores de $\mathrm{Mg}$ e $\mathrm{S}$ seguiram a mesma tendência do $\mathrm{Ca}$; os teores de $\mathrm{Al}$ na solução do solo não foram considerados tóxicos.
\end{abstract}

Palavras-chave: Agricultura orgânica. Fertilidade do solo. Nutrição mineral. Semiárido.

ABSTRACT: Agroecosystems are systems that try to imitate natural ecosystems; and agroecological management consists of a set of practices for this purpose. The objective of this research was to study the soil fertility and mineral nutrition of smallholder farms submitted to agroecological management in four municipalities of the Brazilian semi-arid region, two in Brejo (Arara and Remígio) and two in Cariri (Sumé and Prata) of the Paraíba. In each of these municipalities were studied two properties that had in common the fact of being small, use family labor and practices of organic agriculture, an agriculture of the agroecological type. The crops studied were corn, beans, cotton, fababean, cassava and pumpkin. The main results were: the soil $\mathrm{pH}$ is slightly below the range considered suitable for the most crops; MO is still somewhat low, and sustainable practices should continue to be used to increase it; leaf content of $\mathrm{N}$ was considered adequate for cotton, pumpkim, fababean and cassava, and low for maize and beans; P levels in the leaves were considered low, although their soil content was good; those of $\mathrm{K}$ were considered good only for pumpkim and cassava, so their soil content was good; the contents of Ca were quite variable: low for beans, fababean and cassava; suitable in the pumpkim; and high for cotton and corn; the contents of $\mathrm{Mg}$ and $\mathrm{S}$ followed the same trend of $\mathrm{Ca}$; Al levels in the soil solution were not considered to be toxic.

Keywords: Organic agriculture. Soil fertility Mineral nutrition. Semi-arid.

\footnotetext{
${ }^{\text {I }}$ Possui graduação em Agronomia pela Universidade Federal da Paraíba (1993), mestrado em Agronomia (Fitotecnia) pela Universidade Federal do Ceará (1995) e doutorado em Nutrição Mineral de Plantas (Produção Vegetal) pela Universidade Federal de Viçosa (200I). Atualmente é Pesquisadora A da Empresa Brasileira de Pesquisa Agropecuária com lotação no Centro Nacional de Pesquisa do Algodão (Campina Grande-PB), atuando na área de Nutrição Mineral e Agroecologia.

${ }^{2}$ Graduação em Engenharia Agronômica (1999) e Mestrado em Fitossanidade-Entomologia Agrícola pela Universidade Federal Rural de Pernambuco (2002). Doutor em Agronomia - Entomologia Agrícola pela Universidade Estadual Paulista Júlio de Mesquita Filho (2006), Campus Jaboticabal. Atualmente é pesquisador - EMBRAPA ALGODÃO. Tem experiência na área de Agronomia, com ênfase em Entomologia e Acarologia Agrícola, atuando principalmente nos seguintes temas: algodão, mamona, ácaros de importância agrícola, mudanças climáticas globais e cultivos orgânicos.
} 


\section{INTRODUÇÃO}

Agroecossistemas são sistemas de cultivo que tentam imitar ao máximo os ecossistemas naturais. Para se alcançar essa meta é necessário que o manejo desses sistemas seja feito obedecendo-se a princípios agroecológicos (Cordoba et al., 2020). Numa propriedade agroecológica, o respeito à natureza é um fator de extrema importância (Canuto, 2017). Dessa forma, a reciclagem dos restos orgânicos das culturas é necessária para que o agricultor fique ao máximo possível independente de recursos externos à propriedade (Araújo e Melo, 2010). Outro princípio importante dos agroecossistemas sustentáveis é a diversificação de culturas. $\mathrm{O}$ ambiente homogêneo das monoculturas da agricultura convencional é propício à proliferação de pragas e doenças. Tendo biodiversidade, o sistema torna-se um ambiente favorável para inimigos naturais, além das plantas diversificadas constituírem barreiras físicas à proliferação dos fitopatógenos (Oliveira et al., 2017). Desta forma, nos sistemas agroecológicos de produção, é muito comum práticas como consorciação e rotação de culturas.

$\mathrm{Na}$ Agroecologia, o solo não é considerado apenas como um suporte para as plantas, é um organismo vivo e, como tal, precisa ser alimentado adequadamente (Lemanceau et al., 701 2015). Os sistemas agroecológicos de produção dão ênfase ao aumento da matéria orgânica no solo através de práticas como aplicação de compostos orgânicos e de biofertilizantes, adubação verde e cobertura morta. Tais práticas estimulam a proliferação de organismos vivos no solo, construindo uma fertilidade no sentido holístico (Ondrasek et al., 2019).

A independência do agricultor em relação aos insumos externos, como agrotóxicos e fertilizantes sintéticos, cujo processo de produção depende de recursos fósseis e comprometem a sustentabilidade do planeta, é premissa fundamental na Agroecologia (Borsatto e Carmo, 2012). Ademais, esses insumos contaminam o solo, as águas superficiais e subterrâneas, os animais, os próprios agricultores e os consumidores (AbdElaty et al., 2020).

Além de serem ecologicamente corretos, os sistemas de produção agroecológicos são socialmente justos, contribuindo para a diminuição da pobreza e para a fixação do homem no campo (Gallo et al., 2012). Por suas características peculiares de diversificação e independência de recursos externos, são muito utilizados em propriedades familiares rurais como assentamentos da reforma agrária e comunidades tradicionais como ribeirinhos, indígenas e quilombolas, sendo facilmente aplicáveis (Vielmo et al., 2017). Desta forma, os 
agroecossistemas contribuem para a conservação do solo e da água, a manutenção de bancos de sementes de variedades locais (crioulas) e para a construção da dignidade e da identidade dos pequenos agricultores.

São também economicamente viáveis. As políticas governamentais que estimulam a adoção dos sistemas agroecológicos de produção contribuem perfeitamente para o aumento da renda e da qualidade de vida do produtor rural (Bessa et al., 20r6). A cada dia que passa, o consumidor se torna mais consciente dos danos dos agrotóxicos sobre o meio ambiente e a saúde, dispostos a pagar mais por um produto advindo de práticas agrícolas sustentáveis (Rombaldi et al, 2007). Hoje, se constitui uma realidade a busca por alimentos saudáveis, livres de agrotóxicos.

Políticas agrárias do Governo Federal como o Plano Nacional de Agroecologia e Produção Orgânica (Planapo) e o Programa Nacional para a Redução do Uso de Agrotóxicos (Pronara) têm o potencial de contribuir significativamente para prospectar mudanças sistemáticas no modelo de agricultura convencional que se estabeleceu no Brasil e no Mundo em meados da década de 70, causando danos ambientais e desigualdades sociais, em direção a um modelo que traga segurança alimentar à população e diminuição nos impactos sobre o meio ambiente.

A Agroecologia, portanto, consiste em se utilizar princípios ecológicos na agricultura, fazendo com que os agroecossistemas tenham características cada vez mais parecidas com as dos ecossistemas (Martin e Isaac, 2018). Entretanto, as práticas utilizadas na obtenção dessa finalidade podem variar e esse fato dá origem a alguns tipos de agriculturas de base ecológica como a Agricultura Orgânica (Tamayo, 2013), cuja principal característica é a utilização da matéria orgânica para a melhoria da fertilidade e da biologia do solo; a Agricultura Biológica (Santos, 2012), cujas principais características são o controle biológico e o uso de microrganismos benéficos como as bactérias que fixam $\mathrm{N}$ do ar e os fungos micorrízicos; a Agricultura Biodinâmica (Pfitscher, et al., 2010), cujas principais características são a utilização de preparados biodinâmicos e/ou homeopáticos sobre os vegetais e do calendário astral para orientar as práticas culturais; a Agricultura Natural (Boechat, 2013), cuja principal característica é o não uso de produtos de origem animal como insumos; e a Permacultura (Diniz, 2016), cuja principal característica é a utilização das culturas permanentes nativas nos sistemas de agricultura ecológica, formando sistemas do tipo agroflorestais. 
O Semiárido Nordestino é, fundamentalmente, representado pelo bioma Caatinga, que constitui o Sertão e tem, como traço principal, as frequentes secas, caracterizadas pela ausência, escassez, alta variabilidade espacial e temporal das chuvas. Não é rara a sucessão de anos seguidos de seca. As características do meio ambiente condicionam fortemente os habitantes do Sertão Nordestino a sobreviverem principalmente de atividades econômicas ligadas basicamente à agricultura. Estas se realizam sempre buscando o melhor aproveitamento das condições naturais desfavoráveis, apoiadas muitas vezes em base técnica frágil e utilizando, na maior parte dos casos, tecnologias tradicionais. Apesar da urbanização ocorrida nos últimos anos, a ocupação principal de sua força de trabalho é a agropecuária. A estrutura fundiária é extremamente concentrada, embora seja grande o número de pequenos estabelecimentos ou unidades de produção familiar. Além de suas vulnerabilidades climáticas, grande parte dos solos do Semiárido encontra-se degradada. Os recursos hídricos caminham para a insuficiência ou apresentam níveis elevados de salinização. A flora e a fauna vêm sofrendo a ação predatória do homem. E os frágeis ecossistemas regionais não estão sendo protegidos, ameaçando a sobrevivência de muitas espécies vegetais e animais, e criando riscos à ocupação humana, inclusive associados a processos, em curso, de desertificação (Sudene, 2015).

O objetivo desta pesquisa foi estudar a fertilidade do solo e a nutrição mineral das plantas de pequenas propriedades rurais submetidas ao manejo agroecológico no semiárido brasileiro, mais especificamente nas regiões do Brejo e do Cariri Paraibanos.

\section{METODOLOGIA}

\section{Avaliação do Estado Nutricional das Plantas}

A metodologia consistiu em avaliar o estado nutricional das plantas submetidas a sistemas de manejo agroecológico na zona rural de dois municípios do Brejo (Remígio e Arara) e do Cariri (Sumé e Prata) Paraibanos. Em cada um desses municípios foram coletadas folhas das plantas cultivadas em duas propriedades, perfazendo um total de oito propriedades estudadas ou oito 'unidades pedagógicas'. Nas duas microrregiões, essas propriedades tinham em comum o fato de serem pequenas, utilizarem mão-de-obra praticamente familiar e práticas da agricultura orgânica, que é uma agricultura do tipo agroecológica. 
As culturas implantadas nessas propriedades agroecológicas eram bastante diversificadas, podendo classifica-las fitotecnicamente em:

a) Agrícolas: milho; sorgo; feijões macássar, mulatinho e preto; fava; algodões branco e colorido; gergelim; amendoim; mandioca; girassol.

b) Olerícolas: melancia, abóbora, inhame, cará, batata-doce, maxixe, alface, coentro, cebolinha.

c) Frutíferas: laranja, limão, acerola, goiaba, mamão, manga, pinha, coco.

d) Plantas medicinais: erva-cidreira, erva-doce, capim-santo, boldo, sabugueiro, hortelã, camomila, mastruz.

Todas as propriedades rurais estudadas adotavam práticas agroecológicas como:

a) Adubação orgânica com esterco bovino;

b) Adubação verde utilizando leguminosas adaptadas localmente;

c) Adubação com composto orgânico fabricado na propriedade;

d) Consorciação de culturas;

e) Rotação de culturas;

f) Manutenção de áreas em pousio;

g) Utilização de extratos de plantas para repelir pragas e doenças;

h) Plantio de espécies de plantas repelentes de pragas e doenças.

Uma característica importante desses produtores rurais é o elevado grau de consciência que os mesmos apresentam em relação a importância dos sistemas agroecológicos para o meio ambiente e à saúde do homem e dos animais, destarte seus baixos níveis de escolaridade, refutando explicitamente o uso de agrotóxicos para combater pragas e doenças e de adubos solúveis.

Para uniformizar as culturas estudadas, foram coletadas, em cada uma das oito unidades pedagógicas, folhas das seguintes plantas cultivadas: milho, feijão, algodão, fava, mandioca e jerimum.

Em todas as plantas, convencionou-se coletar a primeira folha recentemente madura, em número de folhas suficientes para representar as plantas cultivadas em cada unidade pedagógica. Em cada propriedade dividíamos a área com a planta cultivada em três partes e, aí, coletávamos folhas em cada uma destas. As folhas eram então acondicionadas em sacos de papel devidamente identificados quanto à cultura e à amostra ( 1,2 ou 3). Em seguida era encaminhada ao Laboratório de Solos e Nutrição de Plantas da Embrapa 
Algodão (Campina Grande-PB) para serem primeiramente secadas em estufa com circulação de ar a mais ou menos $45^{\circ} \mathrm{C}-55^{\circ} \mathrm{C}$. Depois, eram moídas em moinho tipo "bola" e o material era devidamente acondicionado em saco de papel também identificado como viera do campo.

No Laboratório de Nutrição Mineral de Plantas, as amostras sofriam digestão sulfúrica para as determinações de nitrogênio $(\mathrm{N})$, fósforo $(\mathrm{P})$ e potássio $(\mathrm{K})$ e, digestão nitro-perclórica, para as determinações de cálcio $(\mathrm{Ca})$, magnésio $(\mathrm{Mg})$ e enxofre $(\mathrm{S})$. Os teores de $\mathrm{N}, \mathrm{P}$ e $\mathrm{S}$ no tecido vegetal eram determinados por espectrofotometria UVvisível, o teor de $\mathrm{K}$ por fotometria de chama e, os teores de Ca e $\mathrm{Mg}$, por titulometria.

\section{AVALIAÇÃO DO INCREMENTO DA FERTILIDADE DO SOLO}

$\mathrm{Na}$ determinação da fertilidade do solo nas unidades pedagógicas estudadas, cada propriedade foi dividida em três glebas: A, B e C. Em cada uma dessas glebas eram retiradas io amostras simples no método 'zig-zag', nas profundidades de o- 20 e de $20-40$ $\mathrm{cm}$. Depois, essas amostram simples eram juntadas e cuidadosamente homegeneizadas para a obtenção da amostra composta que era, então, colocada em saco plástico devidamente identificado, com etiqueta de papel, quanto à unidade pedagógica, a gleba e a profundidade.

As amostras eram então encaminhadas ao Laboratório de Solos e Nutrição de Plantas da Embrapa Algodão (Campina Grande-PB). Lá elas eram retiradas dos sacos plásticos e colocadas para secar 'ao ar livre' sobre papéis de jornais. Após devidamente secadas, as amostras eram levadas ao Laboratório de Fertilidade do Solo para as seguintes determinações químicas: $\mathrm{pH}$ em $\mathrm{H}_{2} \mathrm{O}(\mathrm{I}: 2,5) ; \mathrm{Ca}^{2+}, \mathrm{Mg}^{2+}, \mathrm{Na}^{+}, \mathrm{K}^{+}, \mathrm{H}+\mathrm{Al}$ e $\mathrm{Al}^{3+}$ $\left(\mathrm{mmol}_{\mathrm{c}} \cdot \mathrm{dm}^{-3}\right) ; \mathrm{P}\left(\mathrm{mg} \cdot \mathrm{dm}^{-3}\right)$ e $\mathrm{MO}\left(\mathrm{g} \cdot \mathrm{kg}^{-1}\right)$.

Após a determinação do $\mathrm{pH}$ em água na proporção de i:2,5 (solo:água) com a ajuda de um potenciômetro com eletrodo combinado, o solo sofria extração com $\mathrm{KCl}$ IM para as determinações de cálcio $(\mathrm{Ca})$, magnésio $(\mathrm{Mg})$ e alumínio $(\mathrm{Al})$. As determinações eram realizadas por titulometria. Para as determinações de fósforo $(\mathrm{P})$, potássio $(\mathrm{K})$ e sódio $(\mathrm{Na})$, o solo sofria a extração por Melich I. O P era determinado por espectrofotometria de absorção atômica; o $\mathrm{K}$ e o $\mathrm{Na}$, por fotometria de chama. Para a determinação da acidez potencial $(\mathrm{H}+\mathrm{Al})$, a extração era feita por acetato de cálcio o,5 $\mathrm{M}$ e pH 7,1; depois a leitura era realizada por titulometria. $\mathrm{Na}$ determinação do teor de matéria orgânica (MO), o solo 
era submetido à extração, por fervura, com bicromato de potássio 0,2 $\mathrm{M}$ e, a leitura, por titulometria.

De posse dos resultados analíticos, calculava-se S (soma de bases), T (ou CTC, capacidade de troca de cátions) e V (percentagem de saturação por bases). A S é a soma das bases $\mathrm{Ca}^{2+}+\mathrm{Mg}^{2+}+\mathrm{K}^{+}$, em $\mathrm{mmol}_{\mathrm{c}} \cdot \mathrm{dm}^{-3} ; \mathrm{T}$ é a soma de $\mathrm{S}+\mathrm{H}+\mathrm{Al} ; \mathrm{e}, \mathrm{V}$, é dado pela seguinte fórmula:

$$
V(\%)=\frac{S}{T} \times 100
$$

\section{RESULTADOS E DISCUSSÃO Estado Nutricional das Plantas}

$\mathrm{Na}$ avaliação do estado nutricional das plantas nas parcelas pedagógicas, chegamos aos seguintes valores médios de teores de nutrientes (Tabela I):

Tabela $\mathrm{I}$ - Teor de macronutrientes e proteína bruta (PB) de folhas de culturas coletadas em propriedades agroecológicas no estado da Paraíba.

\begin{tabular}{|c|c|c|c|c|c|c|c|}
\hline & $\mathrm{N}$ & $\mathrm{PB}$ & $\mathrm{P}$ & $\mathrm{K}$ & $\mathrm{Ca}$ & $\mathrm{Mg}$ & $\mathrm{S}$ \\
\hline & \multicolumn{7}{|c|}{ (...................................... $(\%)$............................. } \\
\hline & \multicolumn{7}{|c|}{ - } \\
\hline Algodão & 3,95 & 24,67 & 0,13 & $\mathrm{I}, 07$ & 3,44 & 0,69 & 0,63 \\
\hline Milho & 2,24 & I 4,00 & o,I9 & $\mathrm{I}, 20$ & 0,83 & 0,35 & 0,24 \\
\hline Feijão & 4,38 & 27,39 & 0,22 & $\mathrm{I}, 38$ & 2,08 & $0,3 \mathrm{I}$ & 0,20 \\
\hline Jerimum & 3,49 & 21,85 & 0,18 & $\mathrm{I}, 93$ & 3,80 & 0,29 & 0,29 \\
\hline Fava & 4,20 & 26,25 & 0,13 & I,63 & $\mathrm{I}, 86$ & 0,44 & 0,49 \\
\hline Mandioca & 3,72 & 23,21 & 0,14 & $\mathrm{I}, 57$ & $\mathrm{I}, \mathrm{I} 3$ & 0,57 & 0,13 \\
\hline
\end{tabular}

$\mathrm{Na}$ avaliação do estado nutricional das culturas do algodão, do milho, do feijão, do jerimum, da fava e da mandioca, em propriedades agroecológicas situadas no Brejo (Remígio e Arara) e no Cariri (Sumé e Prata) paraibanos (Tabela I), verificamos que o nitrogênio, o qual formará os aminoácidos, que são os tijolos para a construção da proteína bruta $(\mathrm{PB})$, encontra-se em nível adequado nas culturas do algodão e do jerimum, porém baixo nas culturas do milho e do feijão e, alto, na fava e mandioca. Das seis culturas, o milho é a única que tem o caminho $\mathrm{C}_{4}$ de assimilação do carbono atmosférico, tendo rápido crescimento (Blätke e Bräutigam, 2019). A sugestão é que os produtores agroecológicos reforcem a adubação orgânica antes da implantação desta cultura. O feijão, por ser uma planta leguminosa, associa-se às bactérias fixadoras de nitrogênio no solo 
(Moreira et al, 2017). Dessa forma, era de se esperar que tivesse um nível de suficiência deste elemento em suas folhas. Alguns fatores de ordem técnica provavelmente estão limitando a associação do rizóbio com a planta hospedeira. Entre esses fatores, pode-se destacar: seca ou encharcamento na fase vegetativa, salinidade ou acidez do solo.

$\mathrm{Na}$ avaliação dos teores de fósforo nas folhas de todas as culturas estudadas e em todas as propriedades agroecológicas, constatou-se valores considerados baixos. É sabido que os solos tropicais 'naturalmente' já apresentam limitação deste elemento, não pela quantidade total, mas pela disponibilidade. O P no solo é altamente fixado pelos óxidos e sesquióxidos de $\mathrm{Fe}$ e $\mathrm{Al}$, tornando-o indisponível às raízes (Vinha et al., 202I). Por ser os adubos fosfatados usados nas agriculturas de base ecológica altamente insolúveis, mais do que os usados na agricultura convencional, a adubação inadequada causa deficiência de P. O ideal é que a adubação seja feita ao plantio, de uma só vez, e numa quantidade superior à demandada pelas plantas, e próximo às sementes e mudas.

Os teores de potássio foram considerados baixos nas culturas do algodão, do milho, do feijão e da fava, e adequados nas culturas do jerimum e da mandioca. Medidas de caráter agroecológico podem ser tomadas pelos agricultores para melhorar a nutrição das culturas com potássio: adubação com estercos, composto orgânico ou vermicomposto; adubação verde; adubação com adubos líquidos orgânicos, como o "supermagro".

Os teores de cálcio nas culturas avaliadas nas propriedades agroecológicas da Paraíba foram bastante variáveis: baixo no feijão, na fava e na mandioca; adequado no jerimum; e alto no algodão e no milho. A calagem é uma prática aceitável em algumas agriculturas de base ecológica. O ideal é que se faça com calcário dolomítico, pois é fornecedor de Ca e Mg. Esses elementos, além de serem nutrientes minerais essenciais, colaboram para manter o $\mathrm{pH}$ do solo numa faixa adequada às culturas (Lange et al., 202I).

Os teores de magnésio e enxofre nas folhas das culturas estudadas, nas diferentes propriedades agroecológicas, seguiram uma tendência semelhante a do cálcio, com exceção da cultura da fava, onde o teor foi considerado alto. A gessagem é uma ótima alternativa para o fornecimento de $\mathrm{S}$ ao solo, além de proporcionar cálcio nas camadas mais profundas, contribuindo para o melhor desenvolvimento das raízes. Entretanto, o gesso não é tão eficiente em corrigir o $\mathrm{pH}$ do solo nas camadas mais superficiais devido a sua alta solubilidade, agindo em subsuperfície (Vilela et al., 2010). 


\section{INCREMENTO DA FERTILIDADE DO SOLO}

$\mathrm{Na}$ avaliação da fertilidade do solo nas camadas de o -20 e de $20-40 \mathrm{~cm}$, nas parcelas pedagógicas do Cariri e do Brejo Paraibanos, chegamos aos seguintes resultados médios (Tabela 2):

Tabela 2 - Atributos relacionados à fertilidade do solo em propriedades agroecológicas do Estado da Paraíba.

\begin{tabular}{|c|c|c|c|c|c|c|c|c|c|c|c|c|}
\hline \multirow[t]{2}{*}{ Camada } & $\mathrm{pH}$ & $\mathrm{Ca}^{2+}$ & $\underset{+}{\mathrm{Mg}^{2}}$ & $\mathrm{Na}^{+}$ & $\mathrm{K}^{+}$ & S & $\begin{array}{r}\mathrm{H}+ \\
\mathrm{Al}\end{array}$ & $\mathrm{T}$ & $\mathrm{V}$ & $\mathrm{Al}^{3+}$ & $\mathrm{P}$ & $\begin{array}{l}\text { M. } \\
\text { O. }\end{array}$ \\
\hline & $\begin{array}{c}\text { Águ } \\
\text { a } \\
1: 2,5\end{array}$ & $\ldots$ & -...... & $\ldots$ & $(\mathrm{mr}$ & $\mathrm{l}_{\mathrm{c}} \cdot \mathrm{d}$ & )... & ...... & $(\%)$ & $\begin{array}{c}(\mathrm{mm} \\
\mathrm{ol}_{\mathrm{c}} / \\
\left.\mathrm{dm}^{3}\right)\end{array}$ & $\begin{array}{c}(\mathrm{mg} / \mathrm{d} \\
\left.\mathrm{m}^{3}\right)\end{array}$ & $\begin{array}{c}(\mathrm{g} / \mathrm{k} \\
\mathrm{g})\end{array}$ \\
\hline $0-20 \mathrm{~cm}$ & 5,8 & 53,0 & 16,9 & 2,3 & 3,6 & 80,6 & 24,5 & 105,4 & 68,6 & 2,2 & 46,3 & 12,4 \\
\hline $\begin{array}{l}20-40 \\
\mathrm{~cm}\end{array}$ & 5,9 & 53,6 & 17,6 & 4,6 & $3, \mathrm{I}$ & 84, & $2 \mathrm{I}, 9$ & 105,9 & 72,4 & 1,2 & 39,7 & $\mathrm{II}, 3$ \\
\hline
\end{tabular}

Conforme podemos constatar, os pH's, os quais representam a acidez ativa do solo, ou seja, a concentração de íons $\mathrm{H}^{+}$na solução do mesmo (Braga, 2010), apresentados nas camadas de o -20 e $20-40 \mathrm{~cm}$ dos solos coletadas nas propriedades agroecológicas do Brejo e do Cariri Paraibanos (Tabela 2), estão um pouco abaixo da faixa ideal para a maioria das plantas cultivadas. Vale lembrar que, quanto menor o $\mathrm{pH}$, maior a concentração de íons hidrogeniônicos na solução do solo (Braga, 20Io) e maior a sua acidez.

Os solos brasileiros são ácidos em sua maioria (Albuquerque et al., 2003). A acidez, representada pela presença dos íons $\mathrm{H}^{+}$e $\mathrm{Al}^{+3}$, ocorre pela lixiviação dos nutrientes do solo, retirada dos nutrientes catiônicos pela cultura sem a devida reposição e utilização de fertilizantes ácidos (Brunetto et al., 2019). A calagem tem por objetivo eliminar a acidez do solo e fornecer cálcio e magnésio para as plantas. O cálcio estimula o crescimento das raízes, promovendo uma maior exploração da água e dos nutrientes do solo (Holland et al., 2018).

A calagem ainda tem outros benefícios: aumenta a disponibilidade de fósforo, já que diminui os sítios de fixação no solo; diminui a disponibilidade de alumínio e manganês através da formação de hidróxidos, que não são absorvidos; aumenta a mineralização da matéria orgânica promovendo maior disponibilidade de nutrientes; e favorece a fixação biológica de nitrogênio. Nas propriedades físicas do solo, a calagem aumenta a agregação, 
pois o cálcio é um cátion floculante e, com isso, diminui a compactação (Holland et al., 2018).

Extensas áreas agricultáveis no Brasil apresentam solos com baixa capacidade de troca catiônica; predomínio de cargas dependentes de $\mathrm{pH}$; baixas concentrações de cálcio, magnésio e potássio; e quantidades relativamente elevadas de alumínio trocável, especialmente a baixos valores de $\mathrm{pH}$ (Tiritan et al., 2010).

A determinação da quantidade de calcário a ser utilizada pode ser estabelecida com base nos critérios do $\mathrm{pH}$ referência ou no critério da saturação da capacidade de troca de cátions $\left(\mathrm{CTC}_{\mathrm{pH}}, \mathrm{o}\right)$ por bases (Holland et al., 2019). Um aspecto adicional a ser atendido pela calagem refere-se ao suprimento de magnésio para a planta, que é exigente no nutriente. Desta forma, recomenda-se realizar a calagem de forma a atingir um teor mínimo de $0,5 \mathrm{cmol}_{\mathrm{c}} \cdot \mathrm{dm}^{-3}$ de magnésio no solo (Kacorzyk e Kasperczyk, 2017).

A necessidade de calagem (NC) das culturas a serem implantadas pode ser calculada pela seguinte fórmula (Campanharo et al., 2007):

$$
\mathrm{NC}(\mathrm{t} / \mathrm{ha})=\frac{(\mathrm{V} 2-\mathrm{V} 1) \times \mathrm{T} \times \mathrm{f}}{100}
$$

Onde:

$\mathrm{V}_{\mathrm{I}}=$ Valor da saturação das bases trocáveis do solo, em porcentagem, antes da correção. $(\mathrm{VI}=100 \mathrm{~S} / \mathrm{T})$ sendo $\mathrm{S}=\mathrm{Ca}^{2+}+\mathrm{Mg}^{2+}+\mathrm{K}^{+}\left(\mathrm{cmol}_{\mathrm{c}} \mathrm{dm}^{-3}\right)$;

$\mathrm{V}_{2}=$ Valor da saturação de bases trocáveis que se deseja, conforme a cultura;

$\mathrm{T}=$ capacidade de troca de cátions, $\mathrm{T}=\mathrm{S}+\left(\mathrm{H}+\mathrm{Al}^{3+}\right)\left(\mathrm{cmol}_{\mathrm{c}} \mathrm{dm}{ }^{-3}\right) ; \mathrm{e}$

$\mathrm{f}=$ fator de correção do PRNT do calcário $\mathrm{f}=\mathrm{I00} / \mathrm{PRNT}$.

Entretanto, apesar do $\mathrm{pH}$ um pouco abaixo da faixa ideal, constata-se que a $\mathrm{V}$ (\% de saturação por bases) encontra-se numa faixa ideal para a maioria das plantas cultivadas, que é ao redor de 70\% (Holland et al., 2019).

Os nutrientes essenciais $\mathrm{Ca}, \mathrm{Mg}, \mathrm{K}$ e $\mathrm{P}$ encontram-se em níveis excelentes considerando a média de todas as parcelas pedagógicas no Cariri e no Brejo Paraibanos (Embrapa, 2006; Pauletti, 2004; Sousa et al., 1987). Isso demonstra que práticas agroecológicas são bastante eficientes para a manutenção dos níveis de certos elementos essenciais que a planta necessita para o seu crescimento e desenvolvimento, contribuindo para a independência do agricultor em relação aos insumos que vêm de fora da propriedade (Oliveira, 2017). 
O teor de matéria orgânica no solo (Tabela 2) foi considerado baixo segundo Embrapa (2006). Entretanto, com a implementação continuada das práticas agrícolas sustentáveis, o teor de matéria orgânica tende a aumentar ao longo dos anos, contribuindo para a formação de um solo biologicamente ativo, com boas propriedades físicas e químicas, onde as plantas cultivadas podem se desenvolver plenamente sem o uso de adubos químicos solúveis, que causam danos ao próprio solo, às águas (subterrâneas e superficiais) e à saúde do agricultor e do consumidor (Nascimento et al., 2017).

A acidez potencial do solo, representada pela soma de $\mathrm{H}+\mathrm{Al}$ (Brunetto et al., 2019), foi considerada média, o que corrobora com os valores encontrados para $\mathrm{pH}$ (Tabela 2), os quais representam a acidez ativa. Entretanto, a concentração de íons $\mathrm{Al}^{3+}$, foi considerada baixa, numa faixa que não permite ao mesmo ser tóxico às plantas, demonstrando que a aplicação de práticas agroecológicas contribui significativamente para tornar a acidez do solo em um nível que não é considerado deletério ao pleno desenvolvimento das plantas (Cavalcante et al., 202I).

\section{CONCLUSÕES}

$\mathrm{O} \mathrm{pH}$ nos solos das propriedades agroecológicas está um pouco abaixo da faixa considerada adequada para a maioria das culturas.

A MO dos solos das propriedades agroecológicas ainda está um pouco baixa, devendo as práticas sustentáveis continuarem sendo empregadas para o seu aumento.

$\mathrm{O}$ teor de $\mathrm{N}$ foi considerado adequado nas folhas das culturas do algodão, do jerimum, da fava e da mandioca, e baixo para as culturas do milho e do feijão, necessitando-se de mais $\mathrm{MO}$ no solo para o milho e mais condições favoráveis à fixação simbiótica de $\mathrm{N}$ para o feijoeiro.

Os teores de $\mathrm{P}$ nas folhas de todas as plantas coletadas nas propriedades agroecológicas foram considerados baixos, apesar do seu teor no solo estar bom.

Os teores de $\mathrm{K}$ nas folhas foram considerados bons apenas nas culturas do jerimum e da mandioca, destarte seu teor no solo estar bom.

Os teores de Ca nas folhas foram bastante variáveis: baixo no feijão, na fava e na mandioca; adequado no jerimum; e alto no algodão e no milho. Os teores de $\mathrm{Mg}$ e $\mathrm{S}$ seguiram a mesma tendência, com exceção para folhas de fava, onde o teor foi alto. Entretanto seus teores no solo estão bons. 
Os teores de $\mathrm{Al}$ na solução do solo estão longe dos níveis considerados tóxicos.

\section{REFERÊNCIAS BIBLIOGRÁFICAS}

ABD-ElATY, I.; PUGliESE, L.; ZELENAKOVA, M.; MESAROS, P.; SHINAWI, A. El. Simulation-based solutions reducing soil and groundwater contamination from fertilizers in arid and semi-arid regions: Case study the eastern Nile Delta. Egypt. International Journal of Environmental Research and Public Health, Basel, v. 17, n. 24, p. 9373, 2020. Disponível em: https://doi.org/I0.339o/ijerphi7249373. Acesso em I2 de janeiro de 2022.

ALBUQUERQUE, J. A.; BAYER, C; ERNANI, P. R.; MAFRA, A. L.; FONTANA, E. C. Aplicação de calcário e fósforo e estabilidade da estrutura de um solo ácido. Revista Brasileira de Ciência do Solo, Viçosa, v.27, n. 5, p. 799-8o6, 2003.

ARAÚJO, A. S. F. de; MELO, W. J. de. Soil microbial biomass in organic farming system. Ciência Rural, Santa Maria, v. 40, n. II, p. 2419-2427. 2010.

BESSA, M. M.; VENTURA, M. V. A.; ALVES, L. da S. Agroecologia, sustentabilidade e a necessidade dos movimentos agroecológicos se tornarem políticas públicas. Desafios, Palmas, v. 2, n. 2, p. 181-197, 2016.

BLÄTKE, M-A.; BRÄUTIGAM, A. Evolution of $\mathrm{C}_{4}$ photosynthesis predicted by constraint-based modelling. ELife, Cambridge, v. 8, e49305, p. I-24, 2019. Disponível em: https://doi.org/ro.7554/eLife.49305. Acesso em 13 de janeiro de 2022.

BOECHAT, C. L.; SANTOS, J. A. G.; ACCIOLY, A. M. de A. Net mineralization nitrogen and soil chemical changes with application of organic wastes with 'Fermented Bokashi Compost'. Acta Scientiarum Agronomy, Maringá, v. 35, n. 2, p. 257-265, 2013.

BORSATTO, R.; CARMO, M. do. Agroecologia e sua epistemologia. Interciência, Caracas, v. 37, n. 9, p. 711-716, 2012. 
BRUNETTO, G.; SOUZA, R. O. S.; PICCIN, R.; BELLINASO, R. J. S.; KAMINSKI, J.; CERETTA, C. A.; STEFANEllO, L.; KRAMMES, R.; HINDERSMANN, J.; GATIBONI, L. C. Effectiveness of a rapid soil incubation method for determining potential acidity of soils in Rio Grande do Sul, Brazil. Ciência Rural, Santa Maria, v. 49, n. 2, e20180350, 2019. Disponível em: http://dx.doi.org/10.1590/oro3-8478cr20180350. Acesso em: 13 de janeiro de 2021.

CAMPANHARO, M.; LIRA JUNIOR, M. de A.; NASCIMENTO, C. W. A. do; FREIRE, F. J.; COSTA, J. V. T. da. Avaliação de métodos de necessidade de calagem no Brasil. Caatinga, Mossoró, v. 20, n. I, p. 97-105, 2007.

CANUTO, J. C. Agroecologia: princípios e estratégias para o desenho de agroecossistemas sustentáveis. Redes, Santa Cruz do Sul, v. 22, n. 2, p. 137-151. 2017.

CAVALCANTE, K. L.; DEON, M. D.; SILVA, H. K. P. da. Acidez e matéria orgânica de solo irrigado com efluente de estações de tratamento de esgoto de Petrolina-PE. Revista Semiárido De Visu, Petrolina, v. 4, n. 3, p. I8I-I89, 202I.

CORDOBA, C.; TRIVINO, C.; TORO CALDERON, J.; HIPÓliTO, J. Agroecosystem resilience. A conceptual and methodological framework for evaluation. PLoS ONE, São Francisco, v. I5, n. 4, 2020. Disponível em: http://dxdoi.ezio3.periodicos.capes.gov.br/10.1371/journal.pone.0220349. Acesso em: 12 de janeiro de 2022.

DINIZ, R. F. Permacultura como um estilo de vida sustentável: o olhar da psicologia ambiental. Revista Internacional Interdisciplinar INTERthesis, Florianópolis, v. 13, n. 2, p. I06-II8, 2016.

EMBRAPA. Tecnologias de Produção de Soja. r.ed. Londrina: Embrapa Soja, 2006. 239p.

GALlO, E.; SETTI, A. F. F.; MAGALHÃES, D.; MACHADO, J. M. H.; BUSS, D. F.; FRANCO NETTO, F. de A. Saúde e economia verde: desafios para o desenvolvimento 
sustentável e erradicação da pobreza. Ciência \& Saúde Coletiva, Rio de Janeiro, v.I7, n. 6, p. I457-I468, 2012.

HOllAND, J. E.; BENNETT, A. E.; NEWTON, A. C.; WHITE, P. J.; McKenzie, B. M.; GEORGE, T. S.; PAKEMAN, R. J.; BAILEY, J. S.; FORNARA, D. A.; HAYES, R. C. Liming impacts on soils, crops and biodiversity in the UK: A review. Science of the Total Environment, Amsterdam, v. 610-611, p. 316-332, 2019.

HOLLAND, J. E.; WHITE, P. J.; GLENDINING, M. J.; GOULDING, K. W. T.; McGrath, S. P. Yield responses of arable crops to liming - An evaluation of relationships between yields and soil $\mathrm{pH}$ from a long-term liming experiment. European Journal of Agronomy, Helsink, v. 105, p. 176-I88, 2019.

KACORZYK, P. A.; KASPERCZYK, M. An effect of liming on magnesium content in meadow vegetation and leachate water. Journal of Water and Land Development, Raszyn, v. 34, n. I, p. 147-151, 2017.

KURIHARA, C. H.; VENEGAS, V. H. A.; NEVES, J. C. L. N.; NOVAIS, R. F. de; STAUT, L. A. Faixas de suficiência para teores foliares em algodão e em soja, definidas em função de índices DRIS. Revista Ceres, Viçosa, v. 6o, n. 3, p. 412-419, 2013.

LANGE, A.; CAVAlli, E.; PEREIRA, C. S.; CHAPlA, M. V.; FREDDI, O. da S. Relações cálcio:magnésio e características químicas do solo sob cultivo de soja e milho. Nativa, Sinop, v. 9, n. 3, p. 294-301, 2021.

LEMANCEAU, P.; MARON, P.; MAZURIER, S.; MOUGEL, C.; PIVATO, B.; PLASSART, P.; RANJARD, L.; REVELLIN, C.; TARDY, V.; WIPF, D. Understanding and managing soil biodiversity: a major challenge in agroecology. Agronomy for Sustainable Development, Paris, v. 35, n. I, p. 67-8I, 2015.

MARTIN, A. R.; ISAAC, M. E. Functional traits in agroecology: Advancing description and prediction in agroecosystems. Journal of Applied Ecology, London, v. 55, n. I, p. 5-II, 2018. 
MOREIRA, L. P.; OLIVEIRA, A. P. S.; FERREIRA, E. P. de B. Nodulation, contribution of biological $\mathrm{N}_{2}$ fixation, and productivity of the common bean (Phaseolus vulgaris L.) inoculated with rhizobia isolates. Australian Journal of Crop Science, Lismore, v. II, n. 6, p. 644-651, 2017.

NASCIMENTO, R. S. de M. P. do; RAMOS, M. L. G.; FIGUEIREDO, C. C. de; SILVA, A. M. M.; SILVA, S. B.; BATISTELLA, G. Soil organic matter pools under management systems in Quilombola Territory in Brazilian Cerrado. Revista Brasileira de Engenharia Agrícola e Ambiental, Campina Grande, v. 21, n. 4, 2017. Disponível em: https://doi.org/I0.1590/I807-I929/agriambi.v2In4p254-260. Acesso em I4 de janeiro de 2022.

OLIVEIRA, E. R. de. Práticas agroecológicas e orgânicas com animais e vegetais na agricultura familiar em Mato Grosso do Sul. RealizAção, Dourados, v. 2, n. 4, p. 18-26, 2017.

OLIVEIRA, L. J. de; BEZERRA NETO, F.; LIMA, J. S. S. de; OLIVEIRA, E. Q. de; MOREIRA, J. N.; SILVA, I. N. Viability of polycultures of arugula-carrot-coriander fertilized with hairy woodrose under different population densities. Revista Brasileira de Engenharia Agrícola e Ambiental, Campina Grande, v. 21, n. 9, p. 6II-617. 2017.

ONDRASEK, G.; BAKIĆ BEGIĆ, H.; ZOVKO, M.; FILIPOVIĆ, L.; MERIÑOGERGICHEVICH, C.; SAVIĆ, R.; RENGEL, Z. Biogeochemistry of soil organic matter in agroecosystems \& environmental implications. Science of the Total Environment, Amsterdam v. 658, p. 1559-1573, 2019.

PAUlETTI, V. Nutrientes: Teores e interpretações. 2.ed. Castro: FUNDAÇÃO ABC, 2004. 86p.

PFITSCHER, E. D.; PFITSCHER, P. C.; SOARES, S. V. Agricultura biodinâmica: uma forma de autossustentabilidade das propriedades rurais. Revista em Agronegócio e Meio Ambiente, Maringá, v. 3, n. 3, p. 179-195, 2010. 
ROMBALDI, C. V.; TIBOLA, C. S.; FACHINELLO, J. C.; SILVA, J. A. percepção de consumidores do Rio Grande do Sul em relação a quesitos de qualidade de frutas. Revista Brasileira de Fruticultura, Jaboticabal, v. 29, n. 3, p. 68I-684, 2007.

SANTOS, J. Q. dos. Agricultura biológica e fertilização. Revista de Ciências Agrárias, Recife, v. 35, n. I, p. 49-58, 2012.

SOUSA, D. M. G. de; MIRANDA, N. L. de; LOBATO, E. Interpretação de análise de terra e recomendação de adubos fosfatados para culturas anuais nos Cerrados. Planaltina: Embrapa-CPAC, 1987. 7p. (Embrapa CPAC. Comunicado Técnico, 51).

SUDENE. Semiárido. Disponível em: http://www.sudene.gov.br/acesso-ainformacao/institucional/area-de-atuacao-da-sudene/semiarido. Acesso em: 24/10/2017.

TAMAYO, A. M. La agricultura orgânica y la agricultura tradicional: uma alternativa intercultural. Letras Verdes: Revista Lationamericana de Estudios Socioambientales, Quito, n. 4, p. 24-26, 2013.

TIRITAN, C. S.; CALONEGO, J. C.; SANTOS, D. H. Efeito da calagem e adubação potássica no crescimento e nutrição da cultura da mamona. Colloquium Agrariae, Presidente Prudente, v. 6, n. 2, p. 27-32. 2010.

VIELMO, O.; DRUMM, E. C.; DEPONTI, C. M. A gestão da agricultura familiar: pluriatividade, diversificação da produção e agricultura orgânica: um estudo de caso da região da campanha. Colóquio, Taquara, v. I4, n. 2, 2017. Disponível em: https://doi.org/I0.26767/coloquio.vi4i2.717. Acesso em: I3 de janeiro de 2022. 
VILELA, L. C.; SANTOS, A. C. dos; BARRETO, P. M.; BRITO, S. dos S.; SILVA, J. E. C. da; OLIVEIRA, L. B. T. de. Propriedades químicas de Latossolo Vermelho em função da aplicação de gessagem e calagem. Revista Acadêmica: Ciências Agrárias e Ambientais, Curitiba, v. 8, n. I, p. 19-27, 2010.

VINHA, A. P. C.; CARRARA, B. H.; SOUZA, E. F. S.; SANTOS, J. A. F. dos; ARANTES, S. A. C. M. Adsorção de fósforo em solos de regiões tropicais. Nativa, Sinop, v. 9, n. I, p. 30-35, 2021. 